\title{
Improvement of FK506 production via metabolic engineering-guided combinational strategies in Streptomyces tsukubaensis
}

\author{
Qing-Bin Wu ${ }^{1,2}$, Xiao-Ying Zhang ${ }^{1,2}$, Xin-Ai Chen ${ }^{1,2}$ and Yong-Quan $\mathrm{Li}^{12^{*}}$ (1)
}

\begin{abstract}
Background: FK506, a macrolide mainly with immunosuppressive activity, can be produced by various Streptomyces strains. However, one of the major challenges in the fermentation of FK506 is its insufficient production, resulting in high fermentation costs and environmental burdens. Herein, we tried to improve its production via metabolic engineering-guided combinational strategies in Streptomyces tsukubaensis.
\end{abstract}

Results: First, basing on the genome sequencing and analysis, putative competitive pathways were deleted. A better parental strain L19-2 with increased FK506 production from 140.3 to $170.3 \mathrm{mg} / \mathrm{L}$ and a cleaner metabolic background was constructed. Subsequently, the FK506 biosynthetic gene cluster was refactored by in-situ promoter-substitution strategy basing on the regulatory circuits. This strategy enhanced transcription levels of the entire FK506 biosynthetic gene cluster in a fine-tuning manner and dramatically increased the FK506 production to $410.3 \mathrm{mg} / \mathrm{mL}$, 1.41 -fold higher than the parental strain L19-2 (170.3 mg/L). Finally, the FK506 production was further increased from 410.3 to $603 \mathrm{mg} / \mathrm{L}$ in shake-flask culture by adding L-isoleucine at a final concentration of $6 \mathrm{~g} / \mathrm{L}$. Moreover, the potential of FK506 production capacity was also evaluated in a 15-L fermenter, resulting in the FK506 production of $830.3 \mathrm{mg} / \mathrm{L}$.

Conclusion: From the aspects of competitive pathways, refactoring of the FK506 biosynthetic gene cluster and nutrients-addition, a strategy for hyper-production and potentially industrial application of FK506 was developed and a hyper-production strain L19-9 was constructed. The strategy presented here can be generally applicable to other Streptomyces for improvement of FK506 production and streamline hyper-production of other valuable secondary metabolites.

Keywords: Streptomyces tsukubaensis, FK506, Hyper-production, Metabolic engineering, Biosynthetic gene cluster refactoring, Regulatory circuits

\section{Background}

FK506 (tacrolimus) is a 23-membered macrolide possessing immunosuppressive activities. Since its first discovery from Streptomyces tsukubaensis in 1987, it has been

\footnotetext{
*Correspondence: lyq@zju.edu.cn

${ }^{1}$ First Affiliated Hospital and Institute of Pharmaceutical Biotechnology, Zhejiang University School of Medicine, Hangzhou 310058, China

Full list of author information is available at the end of the article
}

clinically used as an important immunosuppressant to prevent rejection of transplanted organs and it is approximately 100 -fold more potent than the immunosuppressive compound cyclosporin A [1-6].

Characterization of the entire biosynthetic gene cluster for FK506 has facilitated genetic and biochemical studies on FK506 biosynthesis. The polyketide synthase (PKS) within the cluster incorporates the shikimate-derived original author(s) and the source, provide a link to the Creative Commons licence, and indicate if changes were made. The images or other third party material in this article are included in the article's Creative Commons licence, unless indicated otherwise in a credit line to the material. If material is not included in the article's Creative Commons licence and your intended use is not permitted by statutory regulation or exceeds the permitted use, you will need to obtain permission directly from the copyright holder. To view a copy of this licence, visit http://creativecommons.org/licenses/by/4.0/. The Creative Commons Public Domain Dedication waiver (http://creativeco mmons.org/publicdomain/zero/1.0/) applies to the data made available in this article, unless otherwise stated in a credit line to the data. 
4,5-dihydroxycyclohex-1-enecarboxylic acid (DHCHC) as a starter unit and catalyzes ten successive polyketide chain elongation cycles with two malonyl-CoAs, two methoxymalonyl-ACPs, five methylmalonyl-CoAs and one allylmalonyl-CoA molecules $[7,8]$. The linear polyketide chain was then condensed with pipecolate by the non-ribosomal peptide synthase (NRPS) FkbL and further modified by a series of post-PKS tailoring steps [9-11]. The genes $f k b G / H / I / J / K, t c s A / B / C / D$ and $f k b L$ within the cluster were responsible for biosynthesis of extender units methoxymalonyl-ACP, allylmalonyl-CoA and pipecolate, respectively $[8,12,13]$.

Due to its valuable application, basing on random mutagenesis, medium optimization and genetic manipulation of specific gene targets, tremendous efforts have been dedicated to the enhancement of FK506 production. For example, FK506 production was improved by random mutagenesis in Streptomyces sp. KCCM 11116P [14]. Effect of genetic manipulation of the gene targets inside the FK506 biosynthetic pathway (including $f k b G / H / I / J / K, t c s A / B / C / D, f k b O, f k b L, f k b P, f k b M$, $f k b D$, fkbN and tcs7) [15-19] or outside the FK506 biosynthetic pathway (including dahp, gdhA, accA2, zwf2, mat $B$, mut $A B$ and $p c c)[14,20,21]$ on FK506 production were also evaluated in related Streptomyces strains. Exogenous additives, such as carbon sources, amino acids, specific precursors, were also previously optimized/added to improve FK506 production [21-26]. However, some strategies were only conducted in strains with relatively low FK506 production or some strategies were too costly to use in industrial production. Taking both hyper-production and industrial application into consideration, how to construct a highyielding strain for FK506 production rationally and systematically is of great importance and value.

In this study, basing on an understanding of the biosynthetic machinery, regulatory pathway related to FK506 biosynthesis and its rough metabolic fluxes in S. tsukubaensis L19 (Fig. 1), we developed a combinational strategy and constructed a FK506-hyperproduction strain L19-9. The concepts of competitive pathways, biosynthetic gene cluster refactoring and nutrients supplementation applied in this work were generally applicable to and enable the productionimprovement of other valuable natural products or FK506 in other Streptomyces strains.

\section{Results}

\section{Genomic analysis of S. tsukubaensis L19}

The genome sequence of S. tsukubaensis L19 had been determined by sequencing. The results demonstrated the L19 possessed a chromosome of 7,935,069 bp and had 7,142 predicted protein coding sequences.

Basing on the genome sequence, we performed analysis of secondary metabolite biosynthetic gene clusters with antiSMASH [27] in L19. The results showed that there are 35 putative biosynthetic gene clusters in the genome of S. tsukubaensis L19, 10 of which are PKS/ PKS-NRPS gene clusters (Table 1).

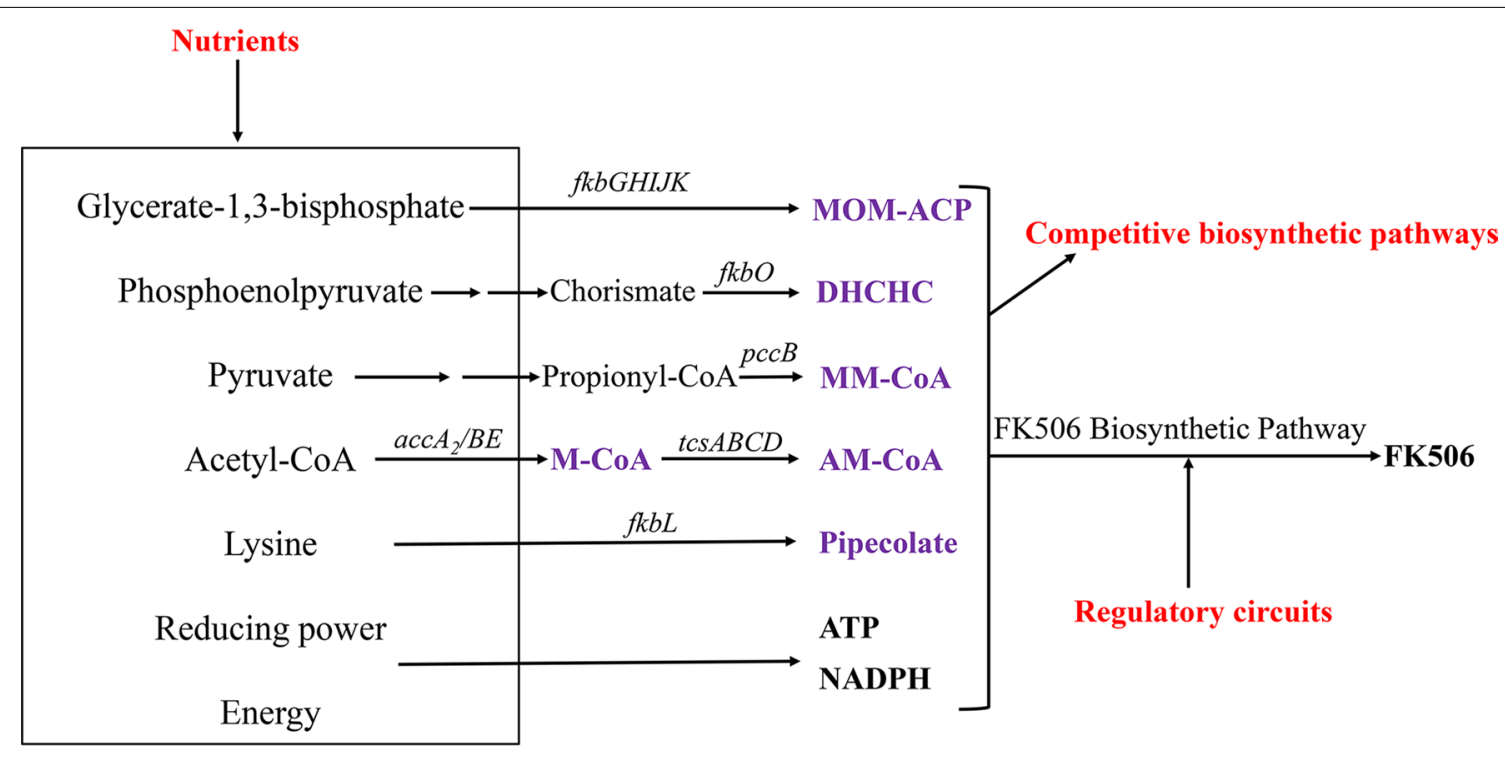

Fig. 1 Schematic representation of metabolic pathways involved in FK506 biosynthesis. Precursors for FK506 biosynthesis were shown in purple. Targets for improved FK506 production were shown in red. Some important genes involved in the biosynthesis of relative precursors were also shown (italics) 
Table 1 Putative PKS/PKS-NRPS gene clusters predicted in S. tsukubaensis L19

\begin{tabular}{llll}
\hline Cluster & Type & Length (bp) & Transcription \\
\hline C1 & Type I PKS & 119,016 & No \\
C2 & Type I PKS & 44,557 & No \\
C3 & Type I PKS & 137,694 & Yes \\
C4 & Type I PKS/NRPS & 74,351 & No \\
C5 & Type II PKS & 86,334 & No \\
C6 & Type II PKS & 72,521 & Yes \\
C7 & Type I PKS & 42,869 & No \\
C8 & FK506 gene cluster & 80,645 & Yes \\
C9 & Type I PKS & 39,818 & Yes \\
C10 & Type I PKS & 44,687 & No \\
\hline
\end{tabular}

\section{Deletion of putatively competitive gene clusters} for a better FK506-producing strain

Although FK506 is the product of a hybrid PKS-NRPS, only one molecule of lysine-derived pipecolate is needed as the extender unit for NRPS and ten molecules of acyl precursors (including two malonyl-CoAs, two methoxymalonyl-ACPs, five methylmalonyl-CoAs and one allylmalonyl-CoA) are needed as the extender units for PKS during biosynthesis of per molecule FK506. Hence, we mainly focused our attention on the putatively competitive PKS or PKS-NRPS gene clusters, which may compete for some common acyl precursors, such as malonyl-CoA. The total RNA was extracted from mycelia cultured $60 \mathrm{~h}$ and expression of the genes encoding core PKS located in these PKS/PKS-NRPS gene clusters was determined by reverse transcription polymerase chain reaction (RT$\mathrm{PCR})$. The results indicated that the genes encoding core PKS in clusters C3, C6 and C9 were all transcribed besides the FK506 gene cluster, which are supposed to compete with FK506 biosynthesis (Additional file 1: Fig. S1).

Due to the difficulty in deleting large DNA fragments in the strain L19, only the genes encoding core PKS in these three clusters were deleted combinatorially in the parental strain L19 and the resultant mutant was named as L19-2. FK506 production of these strains were then monitored by HPLC analyses after fermentation for $168 \mathrm{~h}$. As shown in Fig. 2, the production of FK506 in strain L19-2 increased from 140.3 to $170.3 \mathrm{mg} / \mathrm{mL}$ at $168 \mathrm{~h}, 21.4 \%$ higher than that in strain L19. Meanwhile, no significant difference in biomass was observed among the strains (Fig. 2). Furthermore, by means of full wavelength scanning, we found that the resultant strain L19-2 possessed much cleaner metabolite profiles than L19 in Fm medium (Fig. 3). All these results indicated that the strain L19-2 was a better starting strain for production of FK506 compared with L19.

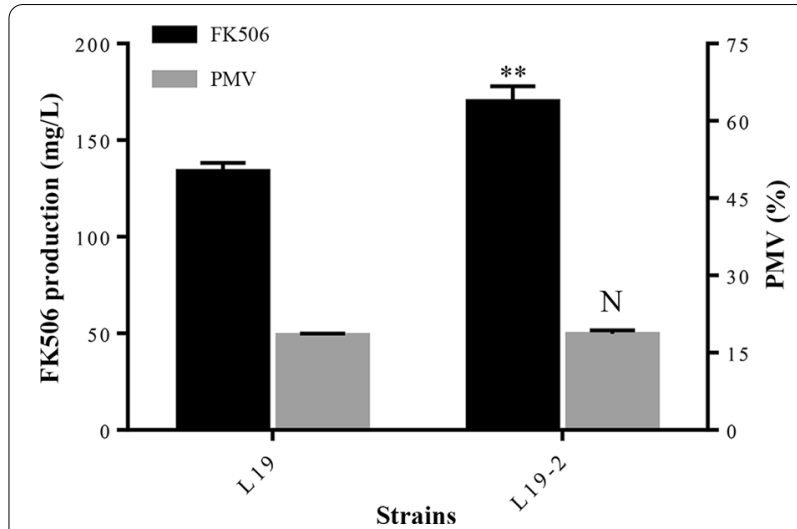

Fig. 2 FK506 production and packed mycelium volume (PMV) in L19 and L19-2 at 168 h, respectively. Error bars showed standard deviations of three independent experiments. The asterisks indicated the statistic significant differences compared with L19, respectively. ${ }^{* *} P<0.05 ; \mathrm{N}$, no significant difference

\section{Refactoring regulatory circuits in the FK506 biosynthetic pathway}

We had previously identified the FK506 biosynthetic gene cluster which is organized as eight transcription units in the strain L19 [17]. The transcription units involved in FK506 biosynthesis are $t c s A / B / C / D, f k b G, f k b B / C / L / K / J /$ $I / H, f k b O / P / A / D / M, t c s 6 / f k b Q / N$, and $t c s 7$ (Fig. 4a). To identify the rate-limiting steps, gene cassettes $t c s A / B$ / $C / D$ and $f k b G / H / I / J / K$, responsible for biosynthesis of the special extender units, were individually cloned into the integration vector pLM1 [28] to construct two plasmids pLM1-1 and pLM1-2, in which these genes were under control of the well-characterized promoter $e r m E p^{*}$. The plasmids were then individually introduced into L19-2 to construct the resultant strains L19-3 and L19-4, respectively. However, compared with the parental strain L192, the strains showed no further improvement in FK506 production (Fig. 4b). Subsequently, another reported gene $f k b O$ responsible for biosynthesis of the starter unit DHCHC was also overexpressed (the resultant plasmid and strain named as pLM1-3 and L19-5, respectively), which surprisingly also showed no significant effect on FK506 production in the strain L19-2 (Fig. 4b).

Considering that the remaining biosynthetic genes were mainly organized as two large transcription units $(f k b B / C / L / K / J / I / H$ and $f k b O / P / A / D / M)$ and their expression were under control of a bidirectional promoter (the intergenic region between $f k b B$ and $f k b O$ ), we then tried to replace this region with stronger constitutive promoter cassettes. In our others work, we had found that the promoters gapdhp and rpsLp [29] possessing comparable activity were much stronger than that of the $e r m E p^{*}$ [30] and $\mathrm{kasOp}^{*}$ [31] promoters in strain L19. Hence, two 

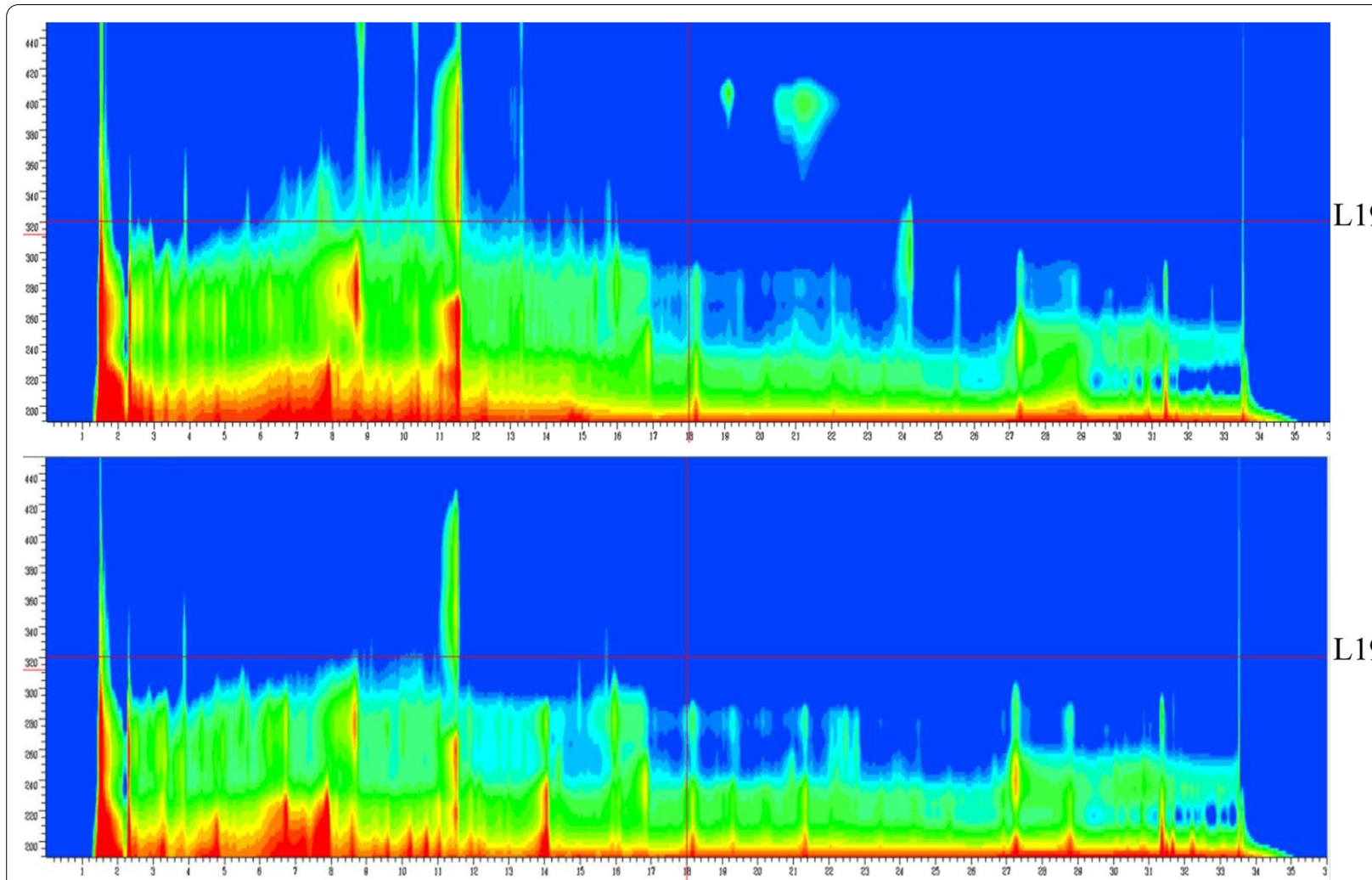

Fig. 3 Analysis of metabolite profiles in L19 and L19-2 by full wavelength scanning. Equal volume of fermentation broths from different strains was harvested, ultrasonically extracted with 2.5 -fold volume of methanol and then subjected to HPLC analysis. The wavelength scanned from 190 to $600 \mathrm{~nm}$

bidirectional promoter cassettes Pke and Pgr were constructed and then used to replace the intergenic region between $f k b B$ and $f k b O$ in situ by $\mathrm{pKC} 1139$-mediated double crossover as shown in Fig. 5, respectively. Unexpectedly, the resultant strains (L19-6 and L19-7, respectively) produced even lower FK506 than the parental strain L19-2 (Fig. 4b), though transcriptional levels of related biosynthetic genes were increased compared with strain L19-2 (Fig. 4c). These results might suggest the importance of the transcriptional level balance between different operons within the gene cluster and we will further discuss this phenomenon in "Discussion" section.

In our previous work, we had verified that overexpression of the pathway-specific regulatory genes $f k b N$ and tcs 7 could enhance the transcriptional levels of all biosynthetic genes [17]. Accordingly, we presumed that substitution of the intergenic region between tcs 6 and tcs7 (a bidirectional promoter region controlling the expression of both $f k b N$ and $t c s 7$ ) with stronger constitutive promoter cassettes could indirectly enhance the transcription levels of all biosynthetic genes in a finetuning manner and thus improve FK506 production. Furthermore, comparing with overexpression-strategy basing on integrative vectors, this substitution strategy could prevent the introduction of additional resistance genes and the putative chromosomal position effect $[32,33]$, which made the resultant strain conducive for further genetic manipulation when needed.

The constructed bidirectional promoter cassettes Pke and $P g r$ were then used to replace the intergenic region between $t c s 6$ and $t c s 7$ in strain L19-2 as mentioned above, respectively. The resultant strains (designated as L19-8 and L19-9, respectively) were confirmed by PCR and further fermented for FK506 production analyses. As was expected, both L19-8 and L19-9 produced higher FK506 compared with L19-2 after fermentation for $168 \mathrm{~h}$ (L19-2, $170.3 \mathrm{mg} / \mathrm{L} ; \mathrm{L} 19-7,350 \mathrm{mg} / \mathrm{L} ; \mathrm{L} 19-8$, $410.3 \mathrm{mg} / \mathrm{L}$ ) (Fig. 6a). Especially, the strain L19-9 possessing stronger promoters showed higher FK506 production than L19-8, suggesting the promoter strength had an important impact on production. Furthermore, the increased transcription levels of the biosynthetic genes $t c s A, f k b G, f k b B$ and $f k b O$, which were located in different transcription units, were also detected in strain L19-9 by qRT-PCR (Fig. 6b). 


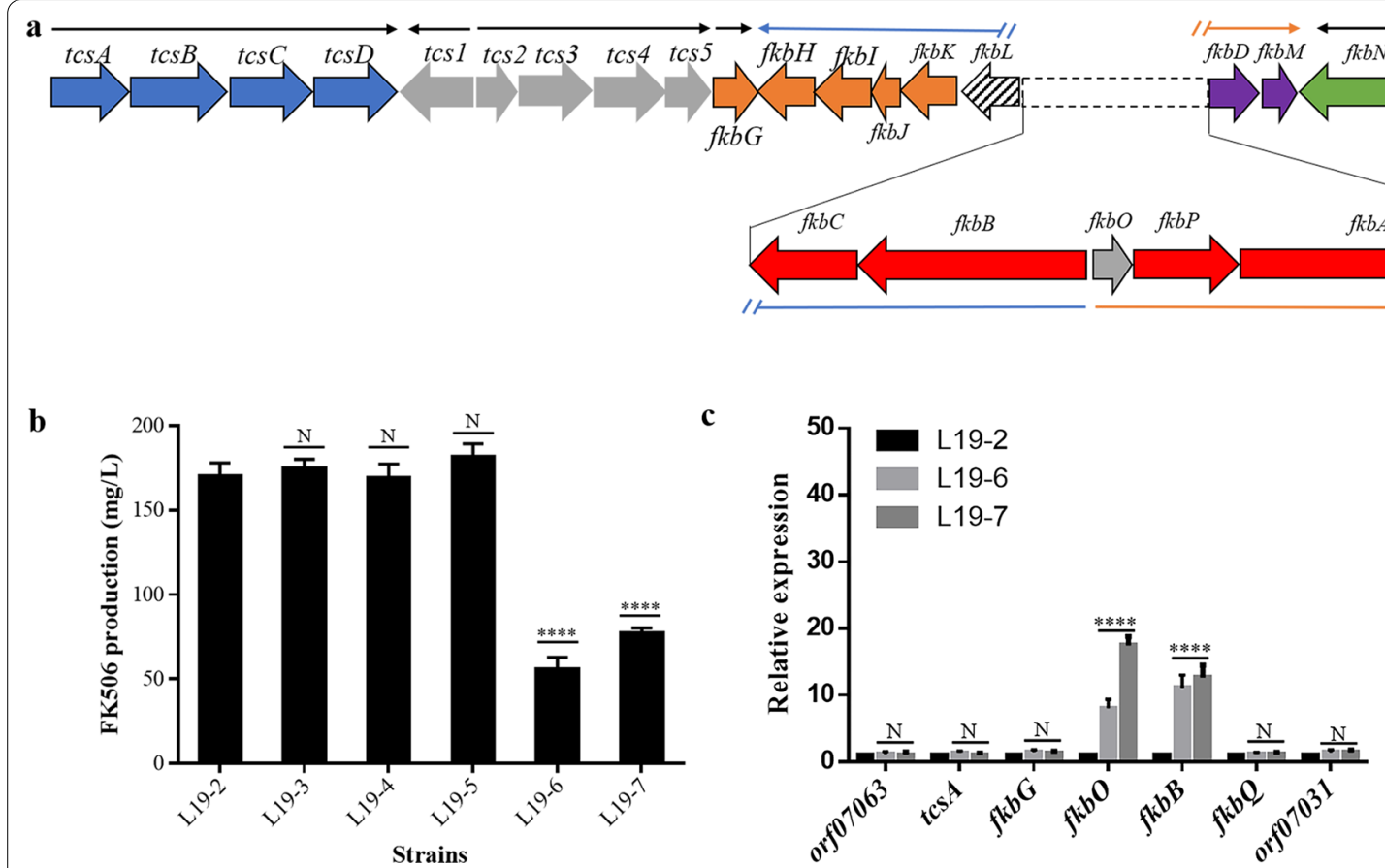

Fig. 4 FK506 biosynthetic gene cluster and analysis of FK506 production and relative expression levels. a Proposed organization of the transcription units $(\rightarrow)$ in FK506 biosynthetic gene cluster. b Effect on FK506 production by overexpressing tCsA/B/C/D (L19-3), fkbG/H/IJJ/K (L19-4) or fkbO (L19-5) and in-situ substitution of the intergenic region between the gene $f k b B$ and $f k b O$ by constructed promoter cassettes (L19-6 and L19-7). c Relative expression levels of selected genes in S. tsukubaensis L19-6 and L19-7 compared with L19-2. Excluding genes located in the FK506 biosynthetic gene cluster, genes residing upstream and downstream regions of the FK506 biosynthetic gene cluster were also included. Each experiment was repeated for three times and error bars showed standard deviations. The asterisks indicated the statistic significant differences compared with L19-2, respectively. ${ }^{* * *} \mathrm{P}<0.0001 ; \mathrm{N}$, no significant difference

$\mathbf{a}$
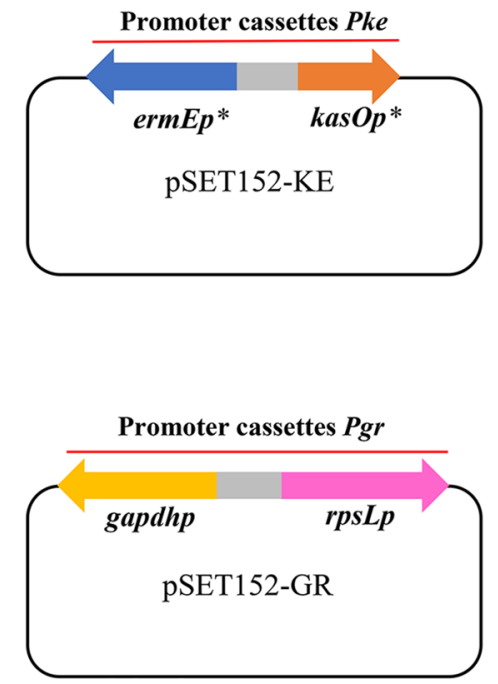

b

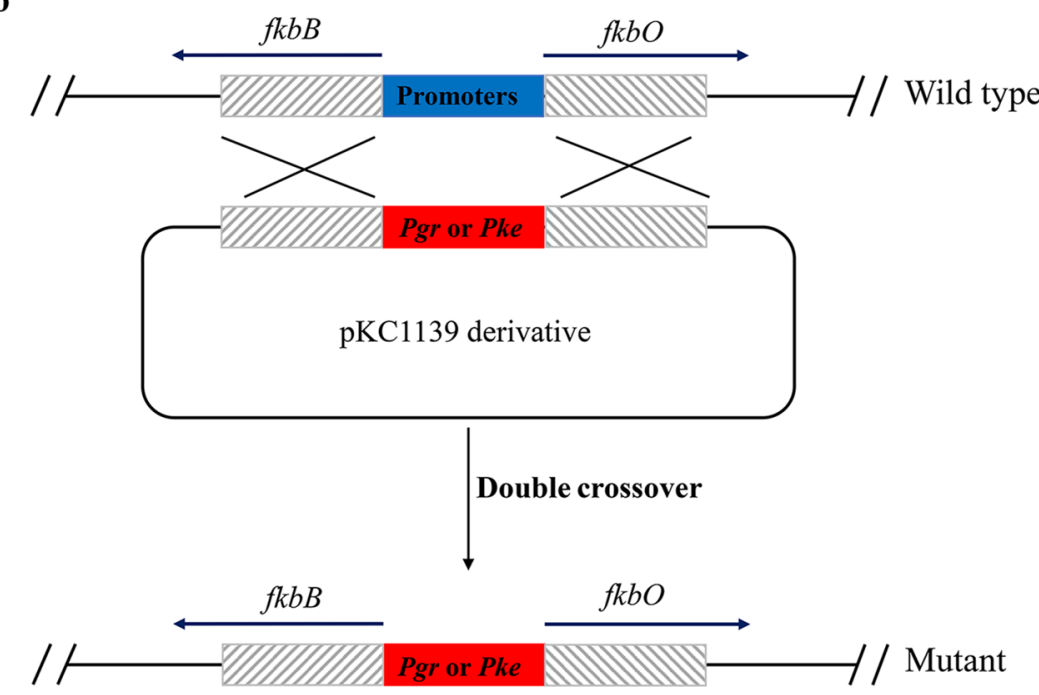

Fig. 5 Schematic representation of the in-situ substitution strategy. a The bidirectional promoter cassettes Pgr and Pke were constructed based on the vector PSET152. The direction of the arrows represented the direction of the promoters. $\mathbf{b}$ Replacement of the intergenic region between $f k b B$ and $\mathrm{fkbO}$ in situ by pKC1139-mediated double crossover 

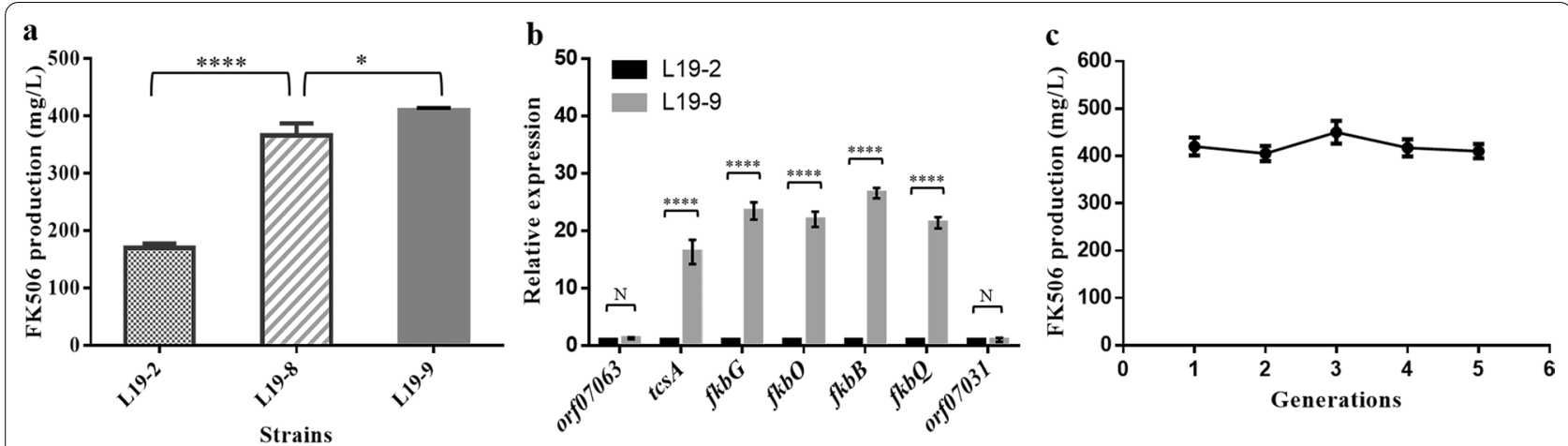

Fig. 6 Analysis of FK506 production, relative expression levels and genetic stability. a FK506 production at $168 \mathrm{~h}$ in strains by substitution of the bidirectional promoter region controlling the expression of both $f k b N$ and $t c s 7$. b Relative expression levels of selected genes in S. tsukubaensis L19-9 compared with L19-2. Excluding genes located in the FK506 biosynthetic gene cluster, genes residing upstream and downstream regions of the FK506 biosynthetic gene cluster were also included. c Production-stability of the high-yielding strain L19-9 in shake-flask culture. The strain was continuously cultured for 5 generations on ISP4 agar plates and the FK506 production was analyzed. Each experiment was repeated for three times and error bars showed standard deviations. The asterisks indicated the statistic significant differences. ${ }^{*} P<0.05 ;{ }^{* * *} P<0.0001 ; \mathrm{N}$, no significant difference

\section{Production-stability of the hyper-production strain L19-9} In industrial production, production-degeneration of the strain is a common problem and the continuous screening process is always laborious and time-consuming. Genetic stability of the hyper-production strain L19-9 was then investigated by continuous passage on ISP4 agar plates. After continuously culturing for 5 generations, FK506 production of each generation was analyzed at $168 \mathrm{~h}$, respectively. The results showed that the production of each generation hardly changed, indicating the production-stability and the potential for industrialization of the high-yielding strain L19-9 (Fig. 6c).

\section{Further improvement of FK506 production by L-isoleucine addition}

It has been previously reported that FK506 production was closely related with primary metabolism and could be improved by genetic manipulation of related genes [20]. Accordingly, related genes including $a c c A 2 B / E$, dahp, $g d h A$ and $z w f 2$ was genetically manipulated individually in strain L19-9 and the effect of the above-mentioned targets on FK506 production was then investigated. However, none of the targets showed obvious effect on FK506 production (data not shown), implying that the already known targets might not be applicable to other strains due to specific genomic contexts and culture conditions. Thus, the medium-optimization for strain L19-9 was then conducted to increase FK506 yield in shake-flask culture. The effects of various nutrients (including glycerol, methyl oleate, L-lysine and L-isoleucine) on FK506 production were examined by individually adding each component to the Fm medium at a final concentration of $5 \mathrm{~g} / \mathrm{L}$. Among the tested components, only L-isoleucine showed positive effect on FK506 production and different concentrations of L-isoleucine were also evaluated to determine the optimum amount added to the Fm medium. The results demonstrated that a final concentration of $6 \mathrm{~g} / \mathrm{L}$ was optimal, with FK506 production increased from 410.3 to $603 \mathrm{mg} / \mathrm{L}$ (Fig. 7a).

To further evaluate the FK506 production capacity for strain L19-9 in the optimized medium, scale-up fermentation was then carried out in a $15-\mathrm{L}$ stirred-tank bioreactor with 8-L $\mathrm{Fm}_{1}$ medium (adding $6 \mathrm{~g} / \mathrm{L}$ of L-isoleucine into Fm medium). The aeration was kept at $1.0 \mathrm{vvm}$ (air/culture volume/min) and the agitation rate was set around 150-250 rpm to maintain dissolved oxygen levels around $35 \%$ during the culture process. It was observed that FK506 production of the strain L19-9 in scale-up fermentation could reach $830.3 \mathrm{mg} / \mathrm{L}$ (Fig. 7b).

\section{Discussion}

To date, tremendous efforts have been made to enhance FK506 production. For example, FK506 production was dramatically increased by combinational strategies (such as random mutation, biosynthetic genes overexpression and exogenous feeding) and two high-yielding strains were constructed, with final FK506 production of $429 \mathrm{mg} / \mathrm{L}$ and $457 \mathrm{mg} / \mathrm{L}$, respectively [16, 34]. Basing on optimization of media and culture conditions in $S$. tsukubaensis NBRC 108819, FK506 production could be increased from $205 \pm 22.0$ to $616 \pm 52.2 \mathrm{mg} / \mathrm{L}$ in a $2.5-\mathrm{L}$ stirred-tank bioreactor [35]. However, there were few studies of an FK506 over-producer constructed rationally and systematically by taking both hyper-production and industrial application into consideration. In present 
a

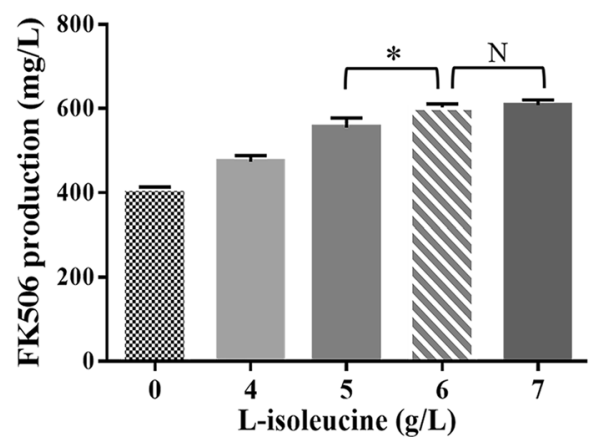

b

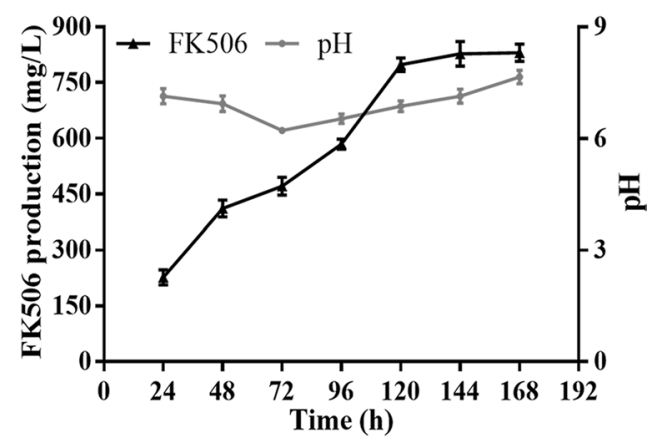

Fig. 7 Effect of L-isoleucine supplement on FK506 production. a Effect of different concentrations of L-isoleucine on FK506 production in shake-flask culture. b FK506 production analyzed in a 15- L stirred-tank bioreactor with 8-L Fm. Error bars show standard deviations of three independent experiments. The asterisks indicated the statistic significant differences. ${ }^{*} P<0.05$; N, no significant difference

work, a strategy for hyper-production and industrial application of FK506 was developed and FK506 production was increased from 140.3 to $830.3 \mathrm{mg} / \mathrm{L}$.

The chassis of Streptomyces refers to the engineered strains suitable for hetero-expression, in which the energy and precursor pool was improved to increase production of desired products [36, 37]. For production-improvement of known products in its native strain, some strategies used in the construction of chassis can also be taken into consideration. Each Streptomyces contains a wide range of biosynthetic gene clusters [38, 39] and deletion of the putatively competitive pathways might increase the production of desired products $[40,41]$.Inspired by these studies, biosynthetic gene clusters (mainly PKS/PKSNRPS gene clusters) in S. tsukubaensis L19 were also analyzed and core PKS located in transcription-active gene clusters were deleted, creating a better strain L19-2 with a cleaner metabolic background and making the FK506 production increased by $21.4 \%$.

The detailed understanding of a targeted biosynthetic pathways was essential for rational and systematical engineering. For example, the production of jadomycin B and novobiocin was improved by substitution of the native promoters of related biosynthetic genes with stronger constitutive and inducible promoters, respectively [42, 43]. In our previous work, the FK506 biosynthetic gene cluster, transcription units within this cluster and its pathway-specific regulatory mechanism were illustrated [17]. In strain L19-2, we then focused on refactoring the FK506 biosynthetic gene cluster to further increase FK506 production. For this purpose, putative rate-limiting steps were first analyzed by either overexpression of biosynthesis-related genes or in-situ substitution of the promoter regions. Unexpectedly, no rate-limiting step was found and the FK506 production even decreased by substituting promoters of the core biosynthetic genes with the constructed promoter cassettes
Pke or Pgr. This phenomenon might be explained by the fact that balanced metabolism between cell growth and product formation is critical and the insertion of strong constitutive promoters upstream of biosynthetic genes may cause metabolic disorders [44-46]. The unexpected results indicated that the promoter substitution strategy might vary in different strains and how to enhance the transcription levels of the entire FK506 biosynthetic gene cluster in a precise and fine-tuning manner was crucial. Herein, as proof of this idea, the promoter substitution strategy was subsequently conducted to manipulate expression of the regulatory genes $f k b N$ and $t c s 7$, which successfully and dramatically enhanced expression of the FK506 biosynthetic gene cluster and production of FK506. Furthermore, we also tried to introduce another copy of the regulatory genes ( $f k b N$ and $t c s 7$ ) into strain L19-9, which lead no further improvement of FK506 production. It should be noted that strain L19-9 derived from the in-situ promoter substitution strategy had higher FK506 production and was more conducive for further genetic manipulation and potential industrialization, since only one selectable marker (apramycin resistance gene) could be utilized in this strain and no additional resistance gene was introduced by this in-situ substitution strategy.

Considering that FK506 is produced from common building blocks deriving from primary metabolic pathways, we also evaluated the effects of genes related to primary metabolism and nutrients-addition on FK506 production. By adding L-isoleucine at a final concentration of $6 \mathrm{~g} / \mathrm{L}$, the FK506 production was further increased from 410.3 to $603 \mathrm{mg} / \mathrm{L}$ in shake-flask culture, and the production could reach the highest of $830.3 \mathrm{mg} / \mathrm{L}$ by scale-up fermentation. Previous studies indicated that L-isoleucine could be transformed into acetyl-CoA, succinyl-CoA and propionyl-CoA, enhancing both primary metabolism and precursors for FK506 biosynthesis [16, 
$25,47,48]$. With the guidance of various omics information, future study may focus on identifying dominant gene targets relating to both L-isoleucine-addition and FK506 production, which could be further manipulated to maximize the potential of FK506 production in the industrial strain L19-9.

\section{Conclusions}

In this work, basing on specific features of the FK506producing strain L19 and taking both hyper-production and industrial application into consideration, the FK506 production was rationally and systematically improved from the aspects of competitive pathways, biosynthetic gene cluster refactoring and medium-optimization (Fig. 8). It should be noted that, if necessary, the FK506 production in strain L19-9 could be optimized repeatedly by deeper investigation. Using the same experimental set-up, this strategy presented here can in principle enable the hyper-production of other valuable natural products or FK506 in other Streptomyces strains.

\section{Methods}

\section{Bacterial strains and culture conditions}

Strains used in this work were listed in Additional file 2: Table S1. E. coli TG1 was used as host for plasmid cloning. E. coli ET12567/pUZ8002 was used for conjugation to transfer plasmids into Streptomyces strains. E. coli was cultured in LB liquid medium ( $1 \% \mathrm{w} / \mathrm{v}$ tryptone, $0.5 \% \mathrm{w} / \mathrm{v}$ yeast extract and $1 \% \mathrm{w} / \mathrm{v} \mathrm{NaCl}$ ) or on $\mathrm{LB}$ agar plates at

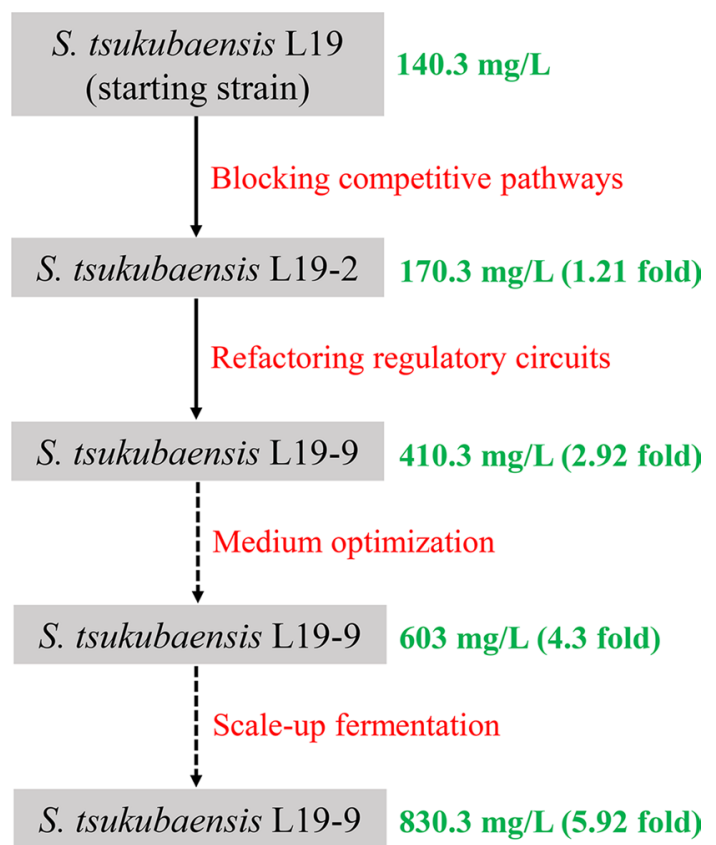

Fig. 8 Related manipulations and FK506 production of the engineered strains constructed in this study $37^{\circ} \mathrm{C}$. All Streptomyces strains were grown on ISP4 solid medium (BD, USA) for spore preparation or conjugation and in TSB (3\% trypticase soy broth, w/v) for preparation of genomic DNA or seed medium. The Fm medium $(5 \% \mathrm{w} / \mathrm{v}$ maltodextrin, $1 \% \mathrm{w} / \mathrm{v}$ yeast power, $3 \% \mathrm{w} / \mathrm{v}$ cotton seed meal, $0.2 \% \mathrm{w} / \mathrm{v} \mathrm{K}_{2} \mathrm{HPO}_{4}, 0.1 \% \mathrm{w} / \mathrm{v} \mathrm{CaCO}_{3}$ and $\mathrm{pH}$ 7.0) and $\mathrm{Fm}_{1}$ medium (adding $6 \mathrm{~g} / \mathrm{L}$ of L-isoleucine into $\mathrm{Fm}$ ) were used as fermentation medium for production of FK506. For culturing E. coli ET12567/pUZ8002 carrying related constructed plasmids used for intergeneric conjugation, antibiotics were supplemented to growth media at the following final concentrations: kanamycin, $50 \mu \mathrm{g} /$ $\mathrm{mL}$; apramycin, $50 \mu \mathrm{g} / \mathrm{mL}$; chloramphenicol, $25 \mu \mathrm{g} / \mathrm{mL}$. For intergeneric conjugation, after co-culturing for about $18 \mathrm{~h}$, apramycin and nalidixic acid were coated on ISP4 agar plates at the final concentration of 50 and $25 \mu \mathrm{g} / \mathrm{mL}$, respectively.

\section{Plasmid construction}

Plasmids and primers used in this work were listed in Additional file 2: Tables S1 and S2, respectively. The genome sequence of $S$. tsukubaensis has been deposited in GenBank (accession number CP070379). The gene cassettes tcsA/ $B / C / D$ and $f k b O$ were amplified from the genomic DNA using primer pairs 1 and 2 , respectively. The fragments were then individually cloned into NdeI/NotI-digested pLM1 [28] using the ClonExpress II one-step cloning kit (Vazyme biotech, Nanjing, China) and confirmed by sequencing, yielding plasmids (pLM1-1 and pLM1-3) for gene overexpression. The gene cassettes $f k b H / I / J / K$ and $f k b G$ were amplified using primer pairs 3 and 4, respectively. The fragments were then cloned into NdeI/NotI-digested pLM1 to yield pLM1-2. For construction of bidirectional promoter cassettes $P k e$ and $P g r$, the $e r m E p^{*}$ was amplified from pLM1 using primer pairs 5. The other promoters (gapdhp, $k a s O p$ *and $r p s L p$ ) were synthesized according to reported literature $[29,31]$ and amplified using primer pairs 6, 7 and 8, respectively. The ermEp* and gapdhp were then individually cloned into BamHI-digested pSET152 [49] using the above cloning kit. The resultant plasmids were digested with $E c o \mathrm{RV}$, and $k a s O p$ *and $r p s L p$ were then individually cloned into the site, yielding plasmids pSET152-KE and pSET152GR containing bidirectional promoter cassettes Pgr and Pke, respectively.

For deletion of the intergenic region between the gene $f k b B$ and $f k b O$, two 1.5-kb DNA fragments flanking the region were amplified from the genomic DNA of $S$. tsukubaensis L19 using primer pairs 9 and 10, respectively, and then cloned into EcoRI/HindIII-digested pKC1139 [49] generating the disruption plasmid pKC1139- $\triangle \mathrm{BO}$. Accordingly, the disruption plasmids pKC1139-C3, pKC1139-C6 and pKC1139-C9 were also constructed as mentioned above, using primer pairs 11, 12, 13, 14, 15 and 16. 
For promoter substitution of the intergenic region between the gene $f k b B$ and $f k b O$, two 1.5-kb DNA fragments flanking the region were amplified using primer pairs 17 and 18. The bidirectional promoter cassette Pke was amplified from pSET152-KE using primer pairs 19 and 20. These three fragments were then cloned into EcoRI/HindIII-digested pKC1139 generating the plasmid pKC1139- $\triangle \mathrm{BOKE}$. Accordingly, other plasmids pKC1139- $\triangle B O G R$, pKC1139- $\triangle$ GR and pKC1139$\triangle \mathrm{KE}$ used for in-situ promoter-substitution were also constructed.

\section{Construction of S. tsukubaensis strains}

The overexpression plasmids were transformed into E. coli ET12567/pUZ8002 and then introduced into $S$. tsukubaensis L19-2 via intergeneric conjugation. To get the over-expression strains, exconjugants were selected on ISP4 agar plates supplemented with apramycin and identified by PCR as described previously [17].

For gene deletion or in-situ substitution, the plasmids derived from pKC1139 were introduced into S. tsukubae$n$ sis by conjugation as mentioned above. Single-crossover-recombination strains were selected by culturing the transformants on ISP4 plates containing $50 \mu \mathrm{g} / \mathrm{mL}$ apramycin at $37{ }^{\circ} \mathrm{C}$. Subsequently, after two rounds of sporulation on plates without antibiotics at $28{ }^{\circ} \mathrm{C}$, double-crossover mutants were selected by their apramycin sensitivity and confirmed by PCR.

\section{RNA extraction and quantitative real-time PCR (qRT-PCR)}

The RNA of $S$. tsukubaensis strains was extracted from mycelia cultured in Fm medium for $36 \mathrm{~h}$, using EASYspin Plus bacteria RNA extract kit (Aidlab Biotech, Beijing, China) according to the manufacturer's instructions. Residual genomic DNA was digested with RNase-free DNase I (TaKaRa, Tokyo, Japan). The cDNA was synthesized using $\mathrm{M}-\mathrm{MLV}$ reverse transcriptase (TaKaRa, Tokyo, Japan) according to the manufacturer's instructions.

To analyze transcription of the 10 PKS/PKS-NRPS gene clusters in L19, the expression of their core PKS was detected by RT-PCR with the primer pairs described in Additional file 2: Table S2. Quantitative real-time polymerase chain reaction (qRT-PCR) was performed using SYBR PremixEx Taq II (TaKaRa, Tokyo, Japan) as described previously $[36,50]$. The sigma factor gene $h r d B$ was used as an internal control to normalize the transcriptional levels. The fold changes of the transcriptional levels were calculated by the $2^{-\Delta \Delta C_{t}}$ method as described previously [51]. The software GraphPad Prism (version 6.02) was used to analyze qRT-PCR data. To compare the difference between the test and control data, $P$ values were calculated by Student's $t$ test. Each experiment was performed in triplicate. PCR primers used here were listed in Additional file 2: Table S2.

\section{Fermentation and analysis of FK506 and packed mycelium volume (PMV)}

The strains were cultured on ISP4 agar plates for about 7-10 days at $28{ }^{\circ} \mathrm{C}$ for sporulation. The spores were then inoculated into $25-\mathrm{mL}$ TSB medium (seed medium) in 250-mL flasks and cultured at $28^{\circ} \mathrm{C}$ and $220 \mathrm{rpm}$ for $24 \mathrm{~h}$. For shake-flask fermentation, the seed culture was inoculated into $30-\mathrm{mL}$ fermentation medium giving a final OD600 of 0.4 , and then cultured at $28^{\circ} \mathrm{C}$ and $220 \mathrm{rpm}$ for $168 \mathrm{~h}$. For fermentation in a 15 -L stirred-tank bioreactor, the seed culture $(400 \mathrm{~mL})$ was then transferred into the fermenter containing fermentation medium $(8 \mathrm{~L})$. The aeration was kept at $1.0 \mathrm{vvm}$ (air/culture volume/min) and the agitation rate was set around $150-250 \mathrm{rpm}$ to maintain dissolved oxygen levels around 35\% during the culture process.

For analysis of FK506, the $200 \mu \mathrm{L}$ culture sample from Fm was ultrasonically extracted with 2.5 -fold volume of methanol. The supernatant was then recovered by centrifugation at $12,000 \mathrm{rpm}$ for $10 \mathrm{~min}$ and injected into a HPLC system (Agilent, Palo Alto, CA, USA) equipped with an Eclipse Plus C18 column $(5 \mathrm{~mm}$, Ø $4.6 \times 150 \mathrm{~mm}$ ), following the program with solvent $\mathrm{A}$ (0.1\% phosphoric acid in water) and solvent $\mathrm{B}$ (acetonitrile): 0-25 $\mathrm{min}, 68 \% \mathrm{~A} / 32 \% \mathrm{~B}$. The UV detection was set at $210 \mathrm{~nm}$. The flow rate was $1 \mathrm{~mL} / \mathrm{min}$ and the column temperature was $60{ }^{\circ} \mathrm{C}$. For calculation of packed mycelium volume (PMV), the culture broth $(1 \mathrm{~mL})$ was centrifuged at $4,000 \times g$ for $4 \mathrm{~min}$. The PMV was then calculated by dividing the volume of packed mycelium by the total volume of the culture broth $(1 \mathrm{~mL})$. The software GraphPad Prism (version 6.02) was used to analyze the data. To compare the difference, $P$ values were calculated by Student's $t$ test. Each experiment was performed in triplicate.

\section{Abbreviations \\ PKS: Polyketide synthase; NRPS: Non-ribosomal peptide synthase; RT-PCR: Reverse transcription polymerase chain reaction; qRT-PCR: Quantita- tive real-time polymerase chain reaction; HPLC: High-performance liquid chromatography.}

\section{Supplementary Information}

The online version contains supplementary material available at https://doi. org/10.1186/s12934-021-01660-w.

Additional file 1: Fig. S1. Analysis of expression of related gene clusters in strain L19 by RT-PCR. Genome DNA (g); complementary DNA (c).

Additional file 2: Table S1. Strains and plasmids used in this work. Table S2. Primers used in this work. 


\section{Acknowledgements}

This work was supported by the National Key R\&D Program of China (Grant Number 2019YFA09005400) and the key project of National Natural Science Foundation of China (Grant Number 31730002).

\section{Authors' contributions}

QBW carried out the experiments and wrote the manuscript. XYZ assisted with the experiments (fermentation and construction of plasmids). YQL, QBW and XAC conceived and designed the experiments. QBW and YQL revised the manuscript. All authors read and approved the final manuscript.

\section{Funding}

This research was sponsored by the National Key R\&D Program of China (2019YFA09005400) and NSFC key projects (31730002).

\section{Availability of data and materials}

The datasets used and/or analyzed during the current study are available from the corresponding author on reasonable request.

\section{Declarations}

\section{Ethics approval and consent to participate}

Not applicable.

\section{Consent for publication}

Not applicable.

\section{Competing interests}

The authors declare that they have no competing interests.

\section{Author details}

${ }^{1}$ First Affiliated Hospital and Institute of Pharmaceutical Biotechnology, Zhejiang University School of Medicine, Hangzhou 310058, China. ${ }^{2}$ Zhejiang Provincial Key Lab for Microbial Biochemistry and Metabolic Engineering, Hangzhou 310058, China.

Received: 1 March 2021 Accepted: 14 August 2021

Published online: 23 August 2021

\section{References}

1. Hashimoto Y, Matsuoka N, Kawakami A, Tsuboi M, Nakashima T, Eguchi K, Tomioka T, Kanematsu T. Novel immunosuppressive effect of FK506 by augmentation of T cell apoptosis. Clin Exp Immunol. 2001;125:19-24.

2. Inamura N, Hashimoto M, Nakahara K, Nakajima Y, Nishio M, Aoki H, Yamaguchi I, Kohsaka M. Immunosuppressive effect of FK506 on experimental allergic encephalomyelitis in rats. Int J Immunopharmacol. 1988;10:991-5.

3. Kodama M, Hanawa H, Zhang S, Saeki M, Koyama S, Hosono H, Miyakita Y, Katoh K, Inomata T, Izumi T, et al. FK506 therapy of experimental autoimmune myocarditis after onset of the disease. Am Heart J. 1993;126:1385-92.

4. Sadaba B, Azanza JR, Garcia Quetglas E, Fernandez V. Treatment with tacrolimus in autoimmune diseases. Rev Med Univ Navarra. 2004;48:24-38.

5. Wallemacq PE, Reding R. FK506 (tacrolimus), a novel immunosuppressant in organ transplantation: clinical, biomedical, and analytical aspects. Clin Chem. 1993;39:2219-28.

6. Zou XM, Yagihashi A, Tsuruma T, Matsuno T, Yamaguchi H, Asanuma K, Sasaki K, Hirata K. Immunosuppressive effect of FK506 on orthotopic liver and small bowel xenotransplantation (xenoOLTx and SBTX). Transplant Proc. 1996;28:1437-9.

7. Ban YH, Park SR, Yoon YJ. The biosynthetic pathway of FK506 and its engineering: from past achievements to future prospects. J Ind Microbiol Biotechnol. 2016;43:389-400.

8. Mo S, Kim DH, Lee JH, Park JW, Basnet DB, Ban YH, Yoo YJ, Chen SW, Park SR, Choi EA, et al. Biosynthesis of the allylmalonyl-CoA extender unit for the FK506 polyketide synthase proceeds through a dedicated polyketide synthase and facilitates the mutasynthesis of analogues. J Am Chem Soc. 2011;133:976-85.
9. Ban YH, Shinde PB, Hwang JY, Song MC, Kim DH, Lim SK, Sohng JK, Yoon YJ. Characterization of FK506 biosynthetic intermediates involved in post-PKS elaboration. J Nat Prod. 2013;76:1091-8.

10. Chen D, Zhang L, Pang B, Chen J, Xu Z, Abe I, Liu W. FK506 maturation involves a cytochrome P450 protein-catalyzed four-electron C-9 oxidation in parallel with a C-31 O-methylation. J Bacteriol. 2013;195:1931-9.

11. Gatto GJ Jr, McLoughlin SM, Kelleher NL, Walsh CT. Elucidating the substrate specificity and condensation domain activity of FkbP, the FK520 pipecolate-incorporating enzyme. Biochemistry. 2005;44:5993-6002.

12. Gatto GJ Jr, Boyne MT 2nd, Kelleher NL, Walsh CT. Biosynthesis of pipecolic acid by RapL, a lysine cyclodeaminase encoded in the rapamycin gene cluster. J Am Chem Soc. 2006;128:3838-47.

13. Wu K, Chung L, Revill WP, Katz L, Reeves CD. The FK520 gene cluster of Streptomyces hygroscopicus var. ascomyceticus (ATCC 14891) contains genes for biosynthesis of unusual polyketide extender units. Gene. 2000;251:81-90

14. Mo S, Lee SK, Jin YY, Oh CH, Suh JW. Application of a combined approach involving classical random mutagenesis and metabolic engineering to enhance FK506 production in Streptomyces sp. RM7011. Appl Microbiol Biotechnol. 2013;97:3053-62.

15. Goranovic D, Blazic M, Magdevska V, Horvat J, Kuscer E, PolakT, SantosAberturas J, Martinez-Castro M, Barreiro C, Mrak P, et al. FK506 biosynthesis is regulated by two positive regulatory elements in Streptomyces tsukubaensis. Bmc Microbiol. 2012;12(1):238.

16. Huang D, Xia M, Li S, Wen J, Jia X. Enhancement of FK506 production by engineering secondary pathways of Streptomyces tsukubaensis and exogenous feeding strategies. J Ind Microbiol Biotechnol. 2013;40:1023-37.

17. Zhang XS, Luo HD, Tao Y, Wang YY, Jiang XH, Jiang H, Li YQ. FkbN and Tcs7 are pathway-specific regulators of the FK506 biosynthetic gene cluster in Streptomyces tsukubaensis L19. J Ind Microbiol Biotechnol. 2016:43:1693-703.

18. Chen D, Zhang Q, Zhang Q, Cen P, Xu Z, Liu W. Improvement of FK506 production in Streptomyces tsukubaensis by genetic enhancement of the supply of unusual polyketide extender units via utilization of two distinct site-specific recombination systems. Appl Environ Microbiol. 2012;78:5093-103.

19. Mo S, Lee SK, Jin YY, Suh JW. Improvement of FK506 production in the high-yielding strain Streptomyces sp. RM7011 by engineering the supply of allylmalonyl-CoA through a combination of genetic and chemical approach. J Microbiol Biotechnol. 2016;26:233-40.

20. Huang D, Li S, Xia M, Wen J, Jia X. Genome-scale metabolic network guided engineering of Streptomyces tsukubaensis for FK506 production improvement. Microb Cell Fact. 2013;12:52.

21. Mo S, Ban YH, Park JW, Yoo YJ, Yoon YJ. Enhanced FK506 production in Streptomyces clavuligerus CKD1119 by engineering the supply of methylmalonyl-CoA precursor. J Ind Microbiol Biotechnol. 2009;36:1473-82.

22. Martinez-Castro M, Salehi-Najafabadi Z, Romero F, Perez-Sanchiz R, Fernandez-Chimeno RI, Martin JF, Barreiro C. Taxonomy and chemically semi-defined media for the analysis of the tacrolimus producer'Streptomyces tsukubaensis.' Appl Microbiol Biotechnol. 2013;97:2139-52.

23. Singh BP, Behera BK. Regulation of tacrolimus production by altering primary source of carbons and amino acids. Lett Appl Microbiol. 2009;49:254-9.

24. Turlo J, Gajzlerska W, Klimaszewska M, Krol M, Dawidowski M, Gutkowska B. Enhancement of tacrolimus productivity in Streptomyces tsukubaensis by the use of novel precursors for biosynthesis. Enzyme Microb Technol. 2012;51:388-95.

25. Xia M, Huang D, Li S, Wen J, Jia X, Chen Y. Enhanced FK506 production in Streptomyces tsukubaensis by rational feeding strategies based on comparative metabolic profiling analysis. Biotechnol Bioeng. 2013;110:2717-30.

26. Yoon YJ, Choi CY. Nutrient effects on FK506, a new immunosuppressant, production by Streptomyces sp. in a defined medium. J Ferment Bioeng. 1997;83:599-603.

27. Blin K, Shaw S, Steinke K, Villebro R, Ziemert N, Lee SY, Medema MH, Weber T. antiSMASH 5.0: updates to the secondary metabolite genome mining pipeline. Nucleic Acids Res. 2019;47:81-7.

28. Mao XM, Zhou Z, Cheng LY, Hou XP, Guan WJ, Li YQ. Involvement of SigT and RstA in the differentiation of Streptomyces coelicolor. FEBS Lett. 2009;583:3145-50. 
29. Shao Z, Rao G, Li C, Abil Z, Luo Y, Zhao H. Refactoring the silent spectinabilin gene cluster using a plug-and-play scaffold. ACS Synth Biol. 2013;2:662-9.

30. Bibb MJ, Janssen GR, Ward JM. Cloning and analysis of the promoter region of the erythromycin resistance gene (ermE) of Streptomyces erythraeus. Gene. 1985;38:215-26.

31. Wang W, Li X, Wang J, Xiang S, Feng X, Yang K. An engineered strong promoter for Streptomycetes. Appl Environ Microbiol. 2013;79:4484-92.

32. Bilyk B, Horbal L, Luzhetskyy A. Chromosomal position effect influences the heterologous expression of genes and biosynthetic gene clusters in Streptomyces albus J1074. Microb Cell Fact. 2017;16:5.

33. Hobbs SL, Kpodar P, DeLong CM. The effect of T-DNA copy number, position and methylation on reporter gene expression in tobacco transformants. Plant Mol Biol. 1990;15:851-64.

34. Ye L, Ye R, Hu F, Wang G. Combination of atmospheric and room temperature plasma (ARTP) mutagenesis, genome shuffling and dimethyl sulfoxide (DMSO) feeding to improve FK506 production in Streptomyces tsukubaensis. Biotechnol Lett. 2021. https://doi.org/10.1007/ s10529-021-03154-6.

35. Patel G, Khobragade TP, Avaghade SR, Patil MD, Nile SH, Kai GY, Banerjee UC. Optimization of media and culture conditions for the production of tacrolimus by Streptomyces tsukubaensis in shake flask and fermenter level. Biocatal Agricult Biotechnol. 2020;29:101803.

36. Bu QT, Yu P, Wang J, Li ZY, Chen XA, Mao XM, Li YQ. Rational construction of genome-reduced and high-efficient industrial Streptomyces chassis based on multiple comparative genomic approaches. Microb Cell Fact. 2019;18:16.

37. Komatsu M, Uchiyama T, Omura S, Cane DE, Ikeda H. Genome-minimized Streptomyces host for the heterologous expression of secondary metabolism. Proc Natl Acad Sci U S A. 2010;107:2646-51.

38. Ohnishi Y, Ishikawa J, Hara H, Suzuki H, Ikenoya M, Ikeda H, Yamashita A, Hattori M, Horinouchi S. Genome sequence of the streptomycinproducing microorganism Streptomyces griseus IFO 13350. J Bacteriol. 2008;190:4050-60.

39. Zhong X, Tian Y, Niu G, Tan H. Assembly and features of secondary metabolite biosynthetic gene clusters in Streptomyces ansochromogenes. Sci China Life Sci. 2013;56:609-18.

40. Lee DW, Ng BG, Kim BS. Increased valinomycin production in mutants of Streptomyces sp. M10 defective in bafilomycin biosynthesis and branched-chain alpha-keto acid dehydrogenase complex expression. J Ind Microbiol Biotechnol. 2015;42:1507-17.

41. Wei $X$, Yunxiang L, Yinghua Z. Enhancement and selective production of oligomycin through inactivation of avermectin's starter unit in Streptomyces avermitilis. Biotechnol Lett. 2006:28:911-6.
42. Dangel V, Westrich L, Smith MCM, Heide L, Gust B. Use of an inducible promoter for antibiotic production in a heterologous host. Appl Microbiol Biotechnol. 2010;87:261-9.

43. Zheng JT, Wang SL, Yang KQ. Engineering a regulatory region of jadomycin gene cluster to improve jadomycin B production in Streptomyces venezuelae. Appl Microbiol Biotechnol. 2007;76:883-8.

44. Ceroni F, Algar R, Stan GB, Ellis T. Quantifying cellular capacity identifies gene expression designs with reduced burden. Nat Methods. 2015:12:415-8.

45. Myronovskyi M, Brotz E, Rosenkranzer B, Manderscheid N, Tokovenko B, Rebets Y, Luzhetskyy A. Generation of new compounds through unbalanced transcription of landomycin A cluster. Appl Microbiol Biotechnol. 2016;100:9175-86.

46. Tan GY, Liu T. Rational synthetic pathway refactoring of natural products biosynthesis in actinobacteria. Metab Eng. 2017;39:228-36.

47. Tang X, Chang L, Gu S, Zhang H, Chen YQ, Chen H, Zhao J, Chen W. Role of beta-isopropylmalate dehydrogenase in lipid biosynthesis of the oleaginous fungus Mortierella alpina. Fungal Genet Biol. 2021;152:103572.

48. Reeves AR, Cernota WH, Brikun IA, Wesley RK, Weber JM. Engineering precursor flow for increased erythromycin production in Aeromicrobium erythreum. Metab Eng. 2004;6:300-12.

49. Bierman M, Logan R, O'Brien K, Seno ET, Rao RN, Schoner BE. Plasmid cloning vectors for the conjugal transfer of DNA from Escherichia coli to Streptomyces spp. Gene. 1992;116:43-9.

50. Wu QB, Chen XA, Lv ZY, Zhang XY, Liu Y, Li YQ. Activation and discovery of tsukubarubicin from Streptomyces tsukubaensis through overexpressing SARPs. Appl Microbiol Biotechnol. 2021;105:4731-41.

51. Livak KJ, Schmittgen TD. Analysis of relative gene expression data using real-time quantitative PCR and the 2(T)(-Delta Delta C) method. Methods. 2001;25:402-8.

\section{Publisher's Note}

Springer Nature remains neutral with regard to jurisdictional claims in published maps and institutional affiliations.
Ready to submit your research? Choose BMC and benefit from:

- fast, convenient online submission

- thorough peer review by experienced researchers in your field

- rapid publication on acceptance

- support for research data, including large and complex data types

- gold Open Access which fosters wider collaboration and increased citations

- maximum visibility for your research: over $100 \mathrm{M}$ website views per year

At BMC, research is always in progress.

Learn more biomedcentral.com/submissions 